\title{
Multi-criteria Analysis of the Waste Management System in a Metropolitan Area
}

\author{
Agnieszka Generowicz ${ }^{1}$, Krzysztof Gaska ${ }^{2}$, and Gabriela Hajduga ${ }^{1, *}$ \\ ${ }^{1}$ Cracow University of Technology, Department of Environmental Engineering, Institute of Water \\ Supply and Environmental Protection, 24 Warszawska Street, 30-155 Cracow, Poland \\ ${ }^{2}$ Silesian University of Technology, Faculty of Energy and Environmental Engineering, Institute of \\ Water and Wastewater Engineering, 18 Konarskiego Street, 44-100 Gliwice, Poland
}

\begin{abstract}
Selection of a waste management strategy for a region is a difficult decision that must take into account various frequently contradictory targets and tasks. This article presents the use of a multi-criteria analysis for estimating and selecting the most profitable selection of a regional-metropolitan waste management system. The final solution should take ecological, economic and social aspects into consideration. It was established that the solutions chosen needed to ensure the following: waste stream reduction, social acceptance, and a profitable economic efficiency index.
\end{abstract}

\section{Introduction}

Waste production is one of the basic elements of human activity. Safe waste management is our particular responsibility towards the natural environment. According to the sustainable development principle, proper waste disposal should provide a technically correct and economically justified solution that least affects the environment and is socially acceptable. Such a solution however, must meet many frequently divergent objectives and is usually a compromise. This article presents a method for finding this solution [1-3].

The article presents an analysis prepared for the purpose of gaining European Funds, which can be treated as an example for this type of goals. In addition, the proposed scenario for implementation had been accepted, implemented and is still in use today.

\section{Literature review}

The use of multi-criteria analysis methods in waste management usually comes down to the choice of the optimal solution in the waste management system specifically designated region and comparisons between each other waste management technologies. The most commonly used method for solving decision-making method is analytical hierarchy (AHP) and linear programming method [4-6]. Overview of methods used in the analysis of waste management has Morrissey [7] in which divided the methods of assessment to methods based on economic indicators, the method of life cycle analysis (LCA) and the analysis of decision-making, and

\footnotetext{
${ }^{*}$ Corresponding author: gabriela.hajduga@gmail.com
} 
among them the most commonly used ELECTRE [8] PROMETHEE [9] AHP [5, 10]. Morrissey [7] shared a positive feature of all multi-criteria analysis approach is the fact that having many individual often conflicting objectives indicates the optimal decisions, allowing for a compromise solution, which can't be said about the analysis of single objective [10-15].

\subsection{Multi-criteria analysis for selecting a waste management system}

Selection of the most favourable solution in a multi-criteria analysis requires the establishment of function that integrates individual characteristics into one overall evaluation. The evaluation parameters subject to integration must be expressed in comparable values and units (standardised) and must be integrated by assigning weights to each individual grade of their respective ranks [1, 5, 10, 15-18]. Evaluating and comparing strategies and selecting the best strategy for a waste management system are possible only through the numeric determination of criteria, that measure the entire system's operation. These criteria are the consequences of the effectiveness of particular waste management strategies and the degree to which established targets are met, which are formulated in general terms. The criteria are chosen in compliance with the sustainable development principle, i.e., within the environmental, economic and social framework $[3,7,9,19]$.

\subsection{Identification of the decision making criteria}

The steps in selecting the most favourable waste management system are as follows: defining the problem; determining the variants of waste management system operations in the region, on the basis of its detailed characteristics and data; describing and adopting calculation methods for particular evaluation criteria; evaluating the functioning of particular variants of the waste management system through measurable evaluation criteria; selecting the most favourable solution from the multi-criteria analysis results based on the accepted evaluation criteria $[17,18]$.

This analysis was conducted for the purpose of acquiring European Union funds for the construction of a waste incineration plant. A summary of this analysis was included in the document prepared by the Bureau for Environmental Engineering and Technology Development in Cracow in 2008 [20, 21].

\section{Description of the object of research: the Bydgoszcz-Torun metropolitan area before modernization - initial state}

The area is located in North-Western Poland is a region with extremely dense industry, which is heavily urbanized. It is in the central part of the Kujawsko-Pomorskie region comprising Bydgoszcz and Toruń, its two capital cities. In addition to these two major cities, the Bydgoszcz Torun Metropolitan Area (BTOM) also encompasses the other communities in the Bydgoski and Toruński districts. In total, it comprises 16 communities, inhabited by approximately 187500 people (at that time when the analysis was carried out). It was assumed that long-term plans of region's waste management will include all of the districts of communities [2, 6, 21-23]. At the time, waste management was conducted using two separate systems in Bydgoszcz and Torun.

The Waste Utilisation Complex, covered an area of 50 ha, was surrounded by forests and was used as the central element in waste management system in Bydgoszcz. The complex, which was launched in 2003, constituted a combination for recovery and stabilization, including a controlled waste disposal site (ballast waste), a mixed waste sorting plant with 
a yearly flow capacity of $60 \mathrm{kt}$, an anaerobic digestion plant (Bioner) for processing organic waste, a power generator complex supplied by biogas acquired from the anaerobic digestion plant and waste yard, a hazardous waste landfill with a capacity of $3500 \mathrm{~m}^{3}$ and an animal burial site. In addition, there were two plants for sorting separately collected recyclables and one plant for sorting mixed waste.

The communal waste management system in Torun was consisted of the operations of the municipal waste landfill. The total capacity of the waste landfill was 3747 thousand cubic meters. Since 2003, apart from waste disposal, composting of green waste and activities related to construction of waste recovery was conducted. The waste sorting plant had the line designed exclusively for sorting selectively collected waste. Within the framework of the communal waste management project, the construction of the following installations were predicted: one sorting line with a yearly capacity of $27 \mathrm{kt}$, an organic waste composting plant with a yearly capacity of $6 \mathrm{kt}$ and a green waste composting plant with a yearly capacity of $3 \mathrm{kt}$.

\section{Determining the waste management system operating variants}

As it was said before, the article present analysis which had been carried out before modernization of waste system in considered area. Because it could have been founded by the UE, to identify the most favourable waste management system for the Bydgoszcz-Torun Metropolitan Area, four different scenarios of the system's modernization were analysed.

In scenario 1, the assumed municipal waste management plans for Bydgoszcz and Torun were based on mechanical biological waste treatment. Waste management in the region was conducted on the basis of two independent systems in Bydgoszcz and Toruń. In Bydgoszcz, it existed in the form of a selective collection system in containers and bags. The waste sorting plan, in its form, could have recovered materials through a selective collection system and biodegradable waste fraction was treated in composting plant.

In Torun, a selective waste collection system was used, which was based on the collection of dry raw material fraction. According to the approved plans, the plant complex was created comprised a non-hazardous and neutral waste yard and a sorting plant with two lines for waste from both selective collection and mixed waste. The mineral sub-sieve fraction and biodegradable waste fraction were separated in the sorting line. From the layer of recyclables materials, separately collected recyclables was partly retrieved. Post-sorting residue was disposed in landfill site, except for a part of the biodegradable waste fraction (up to $6 \mathrm{kt} / \mathrm{year}$ ) that was transferred to the composting plant, composting of green waste and selectively collected biodegradable waste (in a pile-type composting plant), construction debris sorting and bulky waste disassembly were conducted in the newly created plants.

Scenario 2 included a Communal Waste Thermal Treatment Plant (known by its Polish abbreviation, ZTPOK). The ZTPOK mainly received waste after selection had been conducted in the existing (Bydgoszcz) and executed (Toruń) sorting lines. Sorting lines in Bydgoszcz operated at partial capacity. The fine- and biodegradable waste fractions were separated in the KUO lines in Bydgoszcz and in the sorting line in Torun, respectively. In Bydgoszcz, the biodegradable waste fraction was deposited onto BIO-EN-ER heaps, and the sub-sieve fine fraction was used on these heaps as a covering material. In Toruń, a part of the biodegradable waste fraction separated on the sorting line was composted, and the fine fraction was deposited into the non-hazardous and inert waste yard. The average balance of waste destined for incineration plant, in the analysed period, was 180 thousand $\mathrm{Mg} / \mathrm{year}$. The remaining elements of the system operate in a fashion similar to that in scenario 1 .

Scenario 3 also included a thermal treatment. The difference between scenario 3 and scenario 2 was the optimisation of the KUO (Bydgoszcz) sorting line flow capacity. The main purpose of this was to improve the fuel properties of waste through the separation of the 
biodegradable waste and sub-sieve fractions, which were larger than those presented in scenario 2. This scenario allowed the required flow capacity of ZTPOK to be reduced to approximately 150 thousand $\mathrm{Mg} /$ year.

Scenario 4 assumed a lack of BIO-EN-ER heaps in Bydgoszcz and incineration of all residual waste, excluding the sub-sieve fraction, which was separated from the entire stream of waste from Bydgoszcz and in the sorting line in Torun. Such a scenario required the ZTPOK flow capacity to be increased to approximately 200 thousand $\mathrm{Mg} /$ year.

\section{Criteria for evaluating individual waste management scenarios}

For the purpose of fully describing waste management system operation, criteria for characterising a complex system's functioning were adopted and put into three groups. For further information, see Table 1 . The value of criterion 1, was calculated as the amount of waste transferred to waste landfills as a result of the operation of different waste management scenarios in Bydgoszcz and Torun, as a target for 2020. The value of criterion 2, was calculated as the amount of treated and used (not transferred for disposal) organic waste as a result of the operation of different waste management scenarios in Bydgoszcz and Toruń, as a target for 2020. The value of criterion 3, was calculated as the amount of recovered raw materials from the waste stream and high-quality compost suitable for sale.

In scenario 1 , the value of criterion 3 was calculated as the total mass of recovered raw materials in sorting plants and in bulky waste dismantling facilities, and the mass of compost that can be used for agricultural purposes. In scenarios 2, 3, and 4, the value of criterion 3 was calculated as the total mass of recovered raw materials in sorting plants and in bulky waste dismantling facilities, and the mass of high-quality compost from composting of green waste and ferromagnetic recovered from slag produced in the waste thermal treatment plant. However, the recovery of slag for aggregate was not taken into account due to uncertainty about its use.

The value of criterion 4, was calculated as the amount of energy recovered by thermal treatment of waste or energy acquired from biogas incineration specified for the assumed conditions, or as the recovery and use of biogas from the waste landfill.

The impact of the system on the environment is a very important criterion due to the operation of the system, and at the same time very difficult to estimate. At the moment, arise when individual establishments recovery and disposal of waste can accurately determine their impact on the environment. It remains, however, a comprehensive assessment of the impact of the whole system and its impact, while reducing the impact of waste by reducing the flow or harmful character.

The value of criterion 5, was defined by taking into consideration such factors as impact on the atmosphere (including greenhouse gas emission, emission of pollutants accompanying the combustion processes, descending dust emission, and odour emission) and impact on surface and subsurface water (including biogenic and chemical pollutant emissions, acoustic impact, energy consumption, and ground surface use). In the case of the waste management scenarios analysed for the BTOM, determining impact parameters was quite difficult, mainly due to a multitude of installations functioning in the systems. Furthermore, those installations were present in every scenario, while differences in impact were related only to the method of installation usage. Therefore, the method adopted for evaluating the selected parameters relied on experts grading them on a 1-4 scale, where the upper limit represents the least favourable impact on a given environmental component. It was assumed that the sum of the points allocated for each defined parameter of impact was $10(1+2+3+4)$. However, it was possible to obtain identical results for two or more scenarios. The sum of the points representing impact was treated as a summary impact of the individual scenarios on the natural environment. 
Criterion 6, was evaluated according to the plans' entries by the expert method on a $0-1$ scale. Criterion 7, was also evaluated by the expert method on a $0-1$ scale. The value of criterion 8 , was defined on the basis of the above-specified research results.

In Bydgoszcz major survey was conducted among residents of different districts by trained interviewers and included an attempt to 1,000 residents aged 18 to 71 years old. Due to incomplete questionnaires were used to analyse the material from the study 141 people. Among the participants were 64 women and 77 men. Respondents expressed their opinion to those listed in the poll ways of disposing of municipal waste on a 5 - point scale, where point 1 - marked the definite agreement, and points. 5 - marked overwhelming disapproval of the proposed method. Analysis of the severity of attitudes towards various ways of disposing of municipal waste indicated that the inhabitants of Bydgoszcz (the declarations) were the most likely to accept waste incineration process. Almost equally accommodating recycling; reluctant to expand and further use of municipal waste landfills. Most people support the process of thermal treatment of waste (nearly $67.2 \%)$. Almost as many $(66.6 \%)$ in favour of the filing of the waste, and the least people $(16.3 \%)$ welcomes the landfill.

The values of criterion 9 and criterion 10 were calculated by differentiating the outlays and operating costs of the waste management systems in Bydgoszcz and Toruń. Criterion 9 was calculated as the full average monthly financial burden per citizen in Bydgoszcz and neighbouring communities in 2020, while criterion 10 was calculated as the full average monthly financial burden per citizen in Torun and neighbouring communities in 2020.

The value of criterion 11, was calculated as a weighted average of charges for the neutralisation of $1 \mathrm{Mg}$ of waste for the metropolitan area in 2020.

\section{Multi-criteria analysis and selection of the most favourable waste management solution}

Evaluation and comparison of individual waste management system strategies and selection of the best strategy evaluated was possible through the numerical determination of indices measuring the entire system's operation $[16,18,24]$. These indices quantify the performance of individual strategies and the degree of fulfilment of assumed objectives, formulated in general terms.

For the purpose of evaluating the waste management system scenarios described in this article, the criteria listed in Table 1 were adopted.

The solution of the problem was formulated by establishing numerical values for the individual criteria, presenting them in the form of a finite set of numbers, which was the result of the evaluation of the individual waste treatment scenarios considered for the region. Those numbers, organised in a decision matrix, constituted a formal record of a multi-criteria discrete decision problem [18, 21, 23].

Table 1. Criteria for the evaluation of waste management systems in the BTOM [20].

\begin{tabular}{|c|c|c|c|}
\hline Criteria Group & Criterion & Name of criterion & Criterion unit (size) \\
\hline \multirow{4}{*}{$\begin{array}{c}\text { Minimization } \\
\text { and recovery } \\
\text { of waste }\end{array}$} & $\mathrm{K} 1$ & Reduction of the amount of waste & {$[\mathrm{Mg}$ of waste] } \\
\cline { 2 - 4 } & $\mathrm{K} 2$ & $\begin{array}{c}\text { Reduction of the amount of } \\
\text { biodegradable waste }\end{array}$ & {$[\mathrm{Mg}$ of waste] } \\
\cline { 2 - 4 } & $\mathrm{K} 4$ & Recovery of raw materials & {$[\mathrm{Mg}$ of waste] } \\
\cline { 2 - 4 } & $\mathrm{K} 5$ & Energy recovery & IGJ] \\
\hline
\end{tabular}




\begin{tabular}{|c|c|c|c|}
\hline \multirow{3}{*}{$\begin{array}{c}\text { Social and } \\
\text { political }\end{array}$} & $\mathrm{K} 6$ & $\begin{array}{c}\text { Compliance with trends indicated } \\
\text { by the national and regional waste } \\
\text { management plan, and with Polish } \\
\text { legal provisions and EU directives }\end{array}$ & $\begin{array}{c}\text { Expert grade } \\
\text { on 0-1 grade }\end{array}$ \\
\cline { 2 - 4 } & $\mathrm{K} 7$ & $\begin{array}{c}\text { Regionality and perspectivity of the } \\
\text { solution }\end{array}$ & $\begin{array}{c}\text { Expert grade } \\
\text { on 0-1 grade }\end{array}$ \\
\cline { 2 - 4 } & $\mathrm{K} 8$ & Social acceptance & {$[\%]$ (opinion survey) } \\
\hline \multirow{2}{*}{ Economic } & $\mathrm{K} 9$ & $\begin{array}{c}\text { Full average monthly financial } \\
\text { burden per 1 citizen in Bydgoszcz } \\
\text { and in neighbouring communes }\end{array}$ & $\begin{array}{c}\text { [PLN/1 citizen in } \\
\text { Bydgoszcz] }\end{array}$ \\
\cline { 2 - 4 } & $\mathrm{K} 10$ & $\begin{array}{c}\text { Full average monthly financial } \\
\text { burden per 1 citizen in Torun and in } \\
\text { neighbouring communes }\end{array}$ & $\begin{array}{c}\text { [PLN/1 citizen in } \\
\text { Toruń }]\end{array}$ \\
\cline { 2 - 4 } & $\begin{array}{c}\text { Charge for the neutralization of 1 } \\
\text { Mg of waste including penalties for } \\
\text { failure to fulfil the BTOM standards }\end{array}$ & [PLN/year] \\
\hline
\end{tabular}

Table 2. Decision matrix [authors own elaboration].

\begin{tabular}{|c|c|c|c|c|}
\hline \multirow{2}{*}{$\begin{array}{c}\text { Criterion } \\
\text { Number }\end{array}$} & \multicolumn{4}{|c|}{ Individual Startegies } \\
\cline { 2 - 5 } & S1 & S2 & S3 & S4 \\
\hline K1 & 57 & 218.4 & 192.8 & 233.5 \\
\hline K2 & 17.5 & 85.7 & 62.2 & 111.2 \\
\hline K3 & 29.2 & 47.6 & 46.2 & 50.2 \\
\hline K4 & 115 & 803 & 832 & 765 \\
\hline K5 & 22 & 16 & 21 & 11 \\
\hline K6 & 0 & 1 & 1 & 1 \\
\hline K7 & 0 & 1 & 1 & 1 \\
\hline K8 & 62.9 & 64.4 & 64.4 & 64.4 \\
\hline K9 & 12.52 & 14.39 & 16.12 & 14.74 \\
\hline K10 & 17.34 & 20.13 & 20.56 & 20.04 \\
\hline K11 & 456.06 & 528.29 & 567.71 & 534.23 \\
\hline
\end{tabular}

To solve the problem, the compromise programming method was employed. This method applies the concept of arranging individual scenarios according to their distance from the established ideal point with $\mathrm{X}^{\prime}\left(\mathrm{x}_{1}, \mathrm{x}_{2}{ }^{\prime}, \ldots, \mathrm{x}_{\mathrm{M}}{ }^{\prime}\right)$ coordinates, where all $\mathrm{x}_{\mathrm{M}}$ ' coordinates are equal to a maximum value of the accepted standard scale. This method was also used in the analysis of the waste management system in Cracow $[5,18,21]$. The expression for the distance of the examined strategy from the ideal point is as follows:

$$
L_{\alpha}\left(s_{n}\right)=\sum_{m=1}^{M} w_{m}^{\alpha} \cdot\left(x_{m}^{\prime}-r_{N M}^{\prime}\right)^{\alpha}
$$

The best strategy is selected according to the following principle:

$$
s_{j}=\bar{s} \Leftrightarrow L_{\alpha}\left(s_{j}\right)=\min L_{\alpha}\left(s_{j}\right) ; n=1,2, \ldots
$$

$L_{\alpha}\left(s_{n}\right)$ - distance measure of the studied strategy $s_{n}$ from the ideal point, $\bar{s}$ - chosen strategy, $w_{m}$ - weight factor of criterion $\mathrm{m}, x_{m}-\mathrm{m}$-coordinates of utopian point, $r_{N M}$ - normalized value of the criterion, $M$ - number of criteria, $\alpha$ - an exponent, measuring the deviation of the strategy from the utopian point.

The hierarchy of individual criteria is important in the calculation, because it determines the priorities of the participants in the decision-making process. For example (Table 3), in the first case, a weight of 1 was assigned to each criterion. In the second case, all criteria 
associated with minimisation and recovery were given weights of 5 , while the remaining criteria were given weights of 1 . In the final case, the criteria associated with waste minimisation and recovery and social and political criteria were given weights of 5 and economic criteria were given weights of 1 . Table 3 presents the results of the analysis $[18,21]$.

The multi-criteria analysis method permits an additional weighting of criteria through the application of the $\alpha$ exponent in the formulas. This exponent permits an additional weighting of deviations from the ideal point, in proportion to their values. The larger the $\alpha$ value is, the more important the deviation from the ideal point is. Individual calculation cases, which take into account different values of the $\alpha$ coefficient, are included in Table 3.

Calculations were subject to additional restrictions in the form of an acceptance threshold, which was calculated by adding $10 \%$ of the minimum distance from the ideal point. Acceptable scenarios in the table are marked with an asterisk $\left(^{*}\right)$ and are acceptable solutions of the scenario selection problem, in terms of nearness to the ideal point $[18,21]$.

Table 3. The results of the multicriterial analysis for the identified scenarios of the waste management system for the Bydgoszcz - Torun Metropolitan Area [authors own elaboration].

\begin{tabular}{|c|c|c|}
\hline Hierarchy of precedence & \multicolumn{2}{|c|}{ Strategy arrangement } \\
\cline { 2 - 3 } (in order from Table 1) & alpha $=\mathbf{1}$ & alpha $=\mathbf{2}$ \\
\hline $1: 1: 1$ & $\mathrm{~s} 4^{*} \rightarrow \mathrm{s} 2 \rightarrow \mathrm{s} 3 \rightarrow \mathrm{s} 1$ & $\mathrm{~s} 4^{*} \rightarrow \mathrm{s} 2 \rightarrow \mathrm{s} 3 \rightarrow \mathrm{s} 1$ \\
\hline $5: 1: 1$ & $\mathrm{~s} 4^{*} \rightarrow \mathrm{s} 2 \rightarrow \mathrm{s} 3 \rightarrow \mathrm{s} 1$ & $\mathrm{~s} 4^{*} \rightarrow \mathrm{s} 2 \rightarrow \mathrm{s} 3 \rightarrow \mathrm{s} 1$ \\
\hline $10: 1: 1$ & $\mathrm{~s} 4^{*} \rightarrow \mathrm{s} 2 \rightarrow \mathrm{s} 3 \rightarrow \mathrm{s} 1$ & $\mathrm{~s} 4^{*} \rightarrow \mathrm{s} 2 \rightarrow \mathrm{s} 3 \rightarrow \mathrm{s} 1$ \\
\hline $1: 5: 1$ & $\mathrm{~s} 4^{*} \rightarrow \mathrm{s} 2 \rightarrow \mathrm{s} 3 \rightarrow \mathrm{s} 1$ & $\mathrm{~s} 4^{*} \rightarrow \mathrm{s} 2 \rightarrow \mathrm{s} 3 \rightarrow \mathrm{s} 1$ \\
\hline $1: 10: 1$ & $\mathrm{~s} 4^{*} \rightarrow \mathrm{s} 2 \rightarrow \mathrm{s} 3 \rightarrow \mathrm{s} 1$ & $\mathrm{~s} 4^{*} \rightarrow \mathrm{s} 2 \rightarrow \mathrm{s} 3 \rightarrow \mathrm{s} 1$ \\
\hline $1: 1: 2$ & $\mathrm{~s} 4^{*} \rightarrow \mathrm{s} 2 \rightarrow \mathrm{s} 1 \rightarrow \mathrm{s} 3$ & $\mathrm{~s} 2^{*} \rightarrow \mathrm{s} 4 * \rightarrow \mathrm{s} 1 \rightarrow \mathrm{s} 3$ \\
\hline $1: 1: 5$ & $\mathrm{~s} 1^{*} \rightarrow \mathrm{s} 4 \rightarrow \mathrm{s} 2 \rightarrow \mathrm{s} 3$ & $\mathrm{~s} 1^{*} \rightarrow \mathrm{s} 2 \rightarrow \mathrm{s} 4 \rightarrow \mathrm{s} 3$ \\
\hline $1: 1: 10$ & $\mathrm{~s} 1^{*} \rightarrow \mathrm{s} 2 \rightarrow \mathrm{s} 4 \rightarrow \mathrm{s} 3$ & $\mathrm{~s} 1^{*} \rightarrow \mathrm{s} 2 \rightarrow \mathrm{s} 4 \rightarrow \mathrm{s} 3$ \\
\hline $5: 1: 5$ & $\mathrm{~s} 4^{*} \rightarrow \mathrm{s} 2 \rightarrow \mathrm{s} 3 \rightarrow \mathrm{s} 1$ & $\mathrm{~s} 4^{*} \rightarrow \mathrm{s} 2 \rightarrow \mathrm{s} 3 \rightarrow \mathrm{s} 1$ \\
\hline $1: 5: 5$ & $\mathrm{~s} 4^{*} \rightarrow \mathrm{s} 2 \rightarrow \mathrm{s} 1 \rightarrow \mathrm{s} 3$ & $\mathrm{~s} 2 * \rightarrow \mathrm{s} 4 * \rightarrow \mathrm{s} 1 \rightarrow \mathrm{s} 3$ \\
\hline $5: 5: 1$ & $\mathrm{~s} 4^{*} \rightarrow \mathrm{s} 2 \rightarrow \mathrm{s} 3 \rightarrow \mathrm{s} 1$ & $\mathrm{~s} 4^{*} \rightarrow \mathrm{s} 2 \rightarrow \mathrm{s} 3 \rightarrow \mathrm{s} 1$ \\
\hline
\end{tabular}

Based on examination of the results of the multi-criteria analysis, a various observations can be made. The most frequently selected scenarios among 22 calculated cases were the S4 and S2 scenarios (selected 18 times), both of which assume thermal waste treatment as one of the elements of the system. S2 assumes a ZTPOK capacity of 180 thousand $\mathrm{Mg} / \mathrm{year}$, and S4 assumes 200 thousand $\mathrm{Mg}$ /year. In the remaining 4 calculated cases, the S1 scenario was selected, which assumed the continuation of the existing waste treatment system. It is selected when the economic criterion is adopted as the most significant. The S2 scenario, which assumed thermal waste treatment as a system element, with the incineration plants capacity of 150 thousand $\mathrm{Mg}$ annually, was not selected as the most favourable in any of the calculated cases. The recommended S4 and S2 scenarios in principle vary only in the handling of the organic fraction segregated at the KUO in Bydgoszcz. In the S2 scenario, this fraction was deposited on the BIO-EN-ER heap, while in the S4 scenario it is incinerated in the ZTPOK, with the simultaneous deterioration of waste fuel properties. This may require restricting the level of recovery of combustible raw materials (paper and plastics), which would be socially unacceptable. Moreover, this scenario fails to take advantage of the BIO-EN-ER heaps. Between the two, the preferred scenario was the S2 scenario, with the incineration plant operating at a capacity of 180 thousand $\mathrm{Mg} /$ year.

\section{Summary and conclusions}

The selection of a waste management strategy in a region is a difficult task, and must take into account various, frequently contradictory, objectives. 
Multi-criteria analysis is a mathematical tool that may be used to support decisions on the selection of a waste management strategy. However, this requires the identification of a set of evaluation criteria that characterise the requirements for the system in environmental, economic and social terms.

On the basis of the characteristics of the Bydgoszcz-Torun Metropolitan Area, the most favourable waste management strategy for that region was selected. From the results of the analysis, it was possible to ascertain that the $\mathrm{S} 4$ or $\mathrm{S} 2$ scenarios were most frequently selected as the most favourable for that region.

\section{References}

1. V. Belton, T. Stewart, 2002. Multiple Criteria Decision Analysis. An Integrated Approach (Kluwer Academic Publishers, 2002)

2. T. Brechet, H. Tulkens, J. Environ. Manage. 90, 1790-1801 (2009)

3. J. Hokkanen, P. Salminen, Eur. J. Oper. Res. 98(1), 19-36 (1997)

4. Y.P. Li, G.H. Huang, J Environ. Manage. 81, 188-209 (2006)

5. A. Generowicz, J. Kulczycka, Z. Kowalski, M. Banach, J. Environ. Manage. 92(4), 1314-1320 (2011)

6. M. Garfe, S. Tondelli, A. Bonoli, Waste Manage. 29, 2729-2739 (2009)

7. J. Morrissey, J. Browne, Waste Manage. 24, 297-308 (2004)

8. W. Balcerza, A. Generowicz, Z. Mucha, Pol. J. Environ. Stud. 23(3), 983-987 (2014)

9. E. Erkut, A. Karagiannidis, G Perkoulidis, S.A. Tjandra, Eur. J. Oper. Res. 187, 288-298 (2008)

10. A. Generowicz, Pol. J. Environ. Stud. 23(2), 57-63 (2014)

11. P. Aragonés-Beltrán, J.P. Pastor-Ferrando, F. García-García, J. Environ. Manage. 91, 1071-1086 (2010)

12. A.E. Hanandeh, A. El-Zein, Bioresource Technol. 101, 555-561 (2010)

13. G Perkoulidis, A. Papageorgiou, A. Karagiannidis, Waste Manage. 30(7), 1395-1406 (2010)

14. M. Barlaz, G. C. Cekander, N. C. Vasuki, J. Environ. Eng. 129, 583-584 (2003)

15. P. Aragonés-Beltrána, J.A. Mendoza-Rocab, A. Bes-Piáa, M. García-Melónb, E. Parra-Ruizb, J. Hazard. Mater 164(1), 288-295 (2009)

16. A. Klang, P.A. Vikman, H. Btattebř, Conserv. Recycling 38, 317-334 (2003)

17. G. Hajduga, A. Generowicz, E3S Web. Conf 17 (2017)

18. D. A. Rani, A. R. Boccaccini, D. Deegan, C. R. Cheeseman, Waste Manage. 28, 2279-2292 (2008)

19. Ocena strategiczna wykonalności docelowego systemu gospodarki odpadami komunalnymi dla Bydgosko-Toruńskiego Obszaru Metropolitarnego (BTOM) wraz z wyborem wariantów lokalizacji Zakładu Termicznego Przekształcania Odpadów Komunalnych, Przedsiębiorstwo Usługowe „POŁUDNIE II” Biuro Inżynierii Środowiska i Rozwoju Technologii, Kraków (2008)

20. A. Generowicz, J. Ciuła, G. Hajduga, E3S. Web. Conf. 30 (2018)

21. M. Marttunen, V. Belton, Eur. J. Oper. Res. 265(1), 178-194 (2018)

22. K. Jóźwiakowski, K. Mucha, A. Generowicz, Arch. Environ. Prot. 41(3), 76-82 (2015)

23. E. den Boer, A. Jędrczak, Z. Kowalski, J. Kulczycka, R. Szpadt, Waste Manage. 30, 369-377 (2010)

24. M. Czop, 17th International Multidisciplinary Scientific GeoConference SGEM 2017, 17(52), 153-160 (2017) 